\title{
Supply Chain Models with Considerations of Co-Op Advertising and Capacity Constraints
}

\author{
Fan Yang \\ School of Management, Jinan University, Guangzhou, China \\ Email: yang_gg1121@163.com
}

How to cite this paper: Yang, F. (2018) Supply Chain Models with Considerations of Co-Op Advertising and Capacity Constraints. Open Journal of Business and Management, 6, 518-538. https://doi.org/10.4236/ojbm.2018.62039

Received: March 21, 2018

Accepted: April 27, 2018

Published: April 30, 2018

Copyright $\odot 2018$ by author and Scientific Research Publishing Inc. This work is licensed under the Creative Commons Attribution International License (CC BY 4.0).

http://creativecommons.org/licenses/by/4.0/

\section{c) (†) Open Access}

\begin{abstract}
Today's marketing competition focuses on the supply chain members to make its own interests maximize through cooperation. This article establishes a simple secondary supply chain consisting of a retailer and a manufacturer. Through the establishment of a Stackelberg game model and a partnership game model, we study the decision of the member enterprises in the supply chain under the restriction of capacity. The research results show that if the production capacity is smaller, the manufacturer will choose full-load production. If the production capacity is sufficient, the manufacturer will no longer produce more products because its profit may be lost. The lack of production capacity makes the manufacturer not take the initiative to share the advertising costs of retailers. But when the capacity is sufficient, the manufacture shares $1 / 3$ of advertising costs. In addition, whether manufacturers and retailers choose to cooperate in the case of a small capacity, the profit of the supply chain will not change.
\end{abstract}

\section{Keywords}

Supply Chain, Capacity Constraints, Cooperative Advertising

\section{Introduction}

In 2017, the overall advertising market in China showed a stepwise growth. Although the market in the first eight months has steadily increased, it is still in a downward trend compared to 2016. However, in September, the advertising market began to pick up, and the advertising volume reached the highest value in nearly four years. In November, the year-on-year increase in advertising spending reached $8 \%$. This figure was also the highest figure after $9 \%$ year-on-year increase in May 2014. Overall, the advertising market in 2014 developed steadily, but it has faced a shrinking market since 2014. In the second 
half of 2017, there was a trend of continuous increase. The growth rate has also reached a new high. ${ }^{1}$

The rapid growth of new industries, new formats, and new products, the rapid development of the consumer market, and the continuous improvement of consumer spending have all contributed to the increase in advertising demand.

Advertising means propagating specific information to the general public through some form of media. It can be divided into generalized and narrowly defined advertisements. Generalized advertising refers to advertisements that are not for profit; advertisements in narrow sense are generally commercial advertisements, which are intended to enable companies to disseminate products or services to consumers in the market. The main purpose of the increase in market share is to obtain certain economic benefits.

In general, a company takes a variety of marketing strategies to promote products, such as online advertising. Various marketing activities under the line are used to promote products to potential consumers, including product information (price, quality, performance, etc.) and purchased channel information. Through the establishment of a good brand image through advertising to arouse the interest of consumers and generate the intention to buy, it eventually translates into the purchase behavior of consumers.

However, as competition in the global market continues to intensify, companies are more aware that companies rely more on their own internal resources to make it more difficult to cope with market competition, which forces manufacturers and retailers and other economic entities to cooperate gradually. Moreover, the main trend of competition in the market today is no longer the competition among enterprises, but gradually changes to the competition between supply chains. Each member of the supply chain begins to break through the boundaries of traditional enterprises and seek cooperation. They combine their unique advertising resource advantages and effectively integrate them, thereby promoting the production and sales of products and achieving complementary advantages, risk sharing, and benefit-sharing, and thus improve the entire supply chain competitiveness.

In this context, retailers downstream of the supply chain put in advertising, and manufacturers in the upstream of the supply chain share some or all of the costs of advertising. That is, the cooperative advertising mechanism has caused widespread interest. This has gradually become a matter of concern for the entity company or the academic community.

In the process of business operations, products are often unable to achieve unlimited production or sales due to various reasons, such as constraints on capital, labor shortage, low technological level, lagging production methods, insufficient supply of raw materials, etc., thereby limiting the highest performance, there is a problem of capacity constraints.

This article considers that manufacturers and retailers through cooperative

${ }^{1}$ Data source: Nelson Network AIS Full Media Advertising Monitoring. 
advertising to promote market demand, but at the same time the huge increase in demand caused a lack of capacity. It is an important problem that how the various members of the supply chain to make the best decision.

\section{Literature Review}

\subsection{Cooperative Advertising}

The earliest research on supply chain cooperation advertisements at home and abroad was Berger [1]. He used mathematical methods to discuss cooperative advertising between manufacturers and retailers. Many scholars have also conducted in-depth research on the issue of cooperative advertising among supply chains. Most of them have adopted a game theory approach to analyze the optimization of supply chain members and systems by discussing different situations of non-cooperative games and cooperative games. Most of the early papers focused on static research, that is, only one stage was considered. Afterwards, some scholars began to conduct multi-period studies and analyzed the cooperative advertising problems of the supply chain in multiple stages from a dynamic perspective. In addition, previous studies used a simple secondary supply chain. Based on this, some scholars rejoined the competition to expand the research and expand it to one manufacturer and multiple retailers or multiple manufacturers and multiple retail outlets. In this part of this article, we will review the existing research related to domestic and international cooperation advertising according to this logic.

\subsubsection{Static Cooperative Advertising Research}

Most of the existing researches are about the study of single-cycle cooperative advertising in the supply chain, and only consider a simple two-tiered supply chain consisting of a manufacturer and a retailer, and use game theory to solve the profits of manufacturers and retailers in the supply chain. Optimization and system profit optimization issues.

Huang and $\mathrm{Li}$ [2] studied the new market structure that retailers dominated and manufacturers followed, and explored the role of vertical collaborative advertising efficiency between manufacturers and retailers through the sharing rules of brand investment, local advertising expenditure, and advertising expenses. Xie and Wei [3] studied the cooperative advertising and retail price issues of a manufacturer and a retailer's supply chain, and finally confirmed the cooperation by establishing a leader-follower non-cooperative game and a cooperative game model. The game achieves better supply chain coordination. In addition, he also proposed a bargaining model to analyze the problem of how to allocate extra revenue generated by cooperative games.

Karray and Amin [4] studied the effect of competing member companies in the supply chain on advertising and price as a decision variable in cooperative advertising. Zhang and Xie et al. [5] studied the cooperative advertising strategy in the double-deal distribution channel and extended the unilateral participation 
strategy to bilateral participation. Finally, studies show that bilateral participation can indeed coordinate distribution channels under very general demand functions.

\subsubsection{Dynamic Cooperative Advertising Research}

The static cooperative advertising study considers the short-term impact of advertising on product sales. Some scholars have established a multi-stage cooperative advertising model to analyze the dynamic game process in the supply chain.

Jorgensen and Sigué et al. [6] studied the two-stage cooperative advertising problem of a manufacturer and its exclusive retailer. The demand function of the retailer was affected both in the short-term and long-term. Manufacturers support the advertising costs of retailers through the program of co-op advertising. Jorgensen and Zaccour [7] also established a differential game model in which the cooperative advertising problem of a simple two-stage supply chain between a manufacturer and a retailer is considered, and different channel conflicts and coordination are analyzed from a static to a dynamic environment. The influence of prices and advertising on the company's decision-making. He and Prasad et al. [8] established a dynamic mechanism to study cooperative advertising in the supply chain. Manufacturers first announced cooperative advertising policies and wholesale prices, and then retailers determined their best advertising input costs and retail prices. By establishing a random Stackelberg game model, we obtain the best advertising and retail price policy for manufacturers and retailers, and propose a method to coordinate supply chain channels.

\subsubsection{Expansion Research under Competition Relationship}

Most of the earlier studies focused on cooperative advertising only in the simple secondary supply chain, namely the supply chain consisting of a single manufacturer and a single retailer. However, scholars have continuously conducted in-depth research on supply chain cooperation advertisements, added competitive relationships to the study, and explored the situation where one manufacturer corresponds to multiple retailers or multiple manufacturers correspond to multiple retailers, among which there are static cooperation advertisements. Research, as well as dynamic cooperative advertising research, is an extension of previous research. Based on the competitive relationship, the expanded cooperative advertising problem not only discusses the issues discussed in previous studies, but also analyzes whether cooperative advertising can coordinate competitive supply chains.

In Berger's [1] early model, he did not consider the issue of ad sharing, but in the later Bergen and John [9] studies he developed two models to study multiple manufacturers, multiple The degree of differentiation between retailers affects the proportion of advertising sharing. Karray and Zaccour [10] discussed the supply chain structure consisting of two manufacturers and two retailers, and established a model to study the interaction between manufacturer brands and 
competing retailers. The efficiency of cooperative advertising programs is analyzed by comparing two Nash equilibriums of non-cooperative games. In one game, manufacturers do not provide any advertising support to retailers. In another game, manufacturers provide advertising support. They proved that for competitive channels, co-op advertising can indeed increase retailers' marketing efforts and benefit consumers.

\subsection{Cooperative Advertising}

Capacity constraint means that in the course of business operations, due to certain factors, such as the existing conditions of the factory, lack of labor force, low technical level, lagging production methods, insufficient supply of raw materials, etc. The product cannot achieve unlimited production or Sales limit the highest performance of the company. In previous studies, many scholars have made some research on supply chain related issues that consider capacity constraints. These studies mainly include the following aspects.

\subsubsection{Production Decision Problem}

There are many studies on production decision-making under productivity constraints. Cachon and Lariviere [11] studied the manufacturer's capacity allocation decisions and the retailer's ordering decisions. Considers the supply chain of a manufacturer and multiple vendors, where the manufacturer has a production limit, and each vendor secretly informs the manufacturer of its optimal inventory level. If the retailer orders exceed capacity, the manufacturer uses publicly known the allocation mechanism allocates production capacity and describes the process from the retailer's order to the production capacity allocation. Florian and Klein [12] studied the production planning problem of multi-cycle single commodities based on cost and capacity constraints. He calculated the solutions under the conditions of allow backlog and no backlog.

Some scholars also study how to solve the problem of production limitation in the production decision-making. Jonrinaldi and Zhang [13] proposed a comprehensive production and inventory model for a green manufacturing supply chain consisting of multiple raw material manufacturers, multiple component manufacturers, manufacturers, multiple distributors, and multiple retailers. And use it to study the limited manufacturer's contract period and capacity constraints.

After that, the concept of remanufacturing mode emerged, and manufacturing and remanufacturing integrated system is the trend of manufacturing development. Some scholars began to study the issue of capacity constraints under this model. Li and Chen et al. [14] studied remanufacturing production lot decision-making problems under conditions of limited production capacity and alternatives to remanufactured products.

\subsubsection{Supply Chain Coordination}

Hsieh and $\mathrm{Wu}$ [15] took into account the uncertainty in the shared information 
on capacity and demand in the supply chain, and studied the issue of coordination decisions in a supply chain that included an original equipment manufacturer (OEM), a manufacturer, and a distributor.

Kreps and Scheinkman [16] consider a two-stage oligopoly game; two oligopolistic companies produce products at the same time. Then firstly releasing production capacity and then carrying out price competition, and studying the balance issue of investment in production capacity investment at a given point in time. The only equilibrium solution ultimately obtained is the Cournot equilibrium, which shows that the solution to the oligopolistic game depends on the strategic variables used and the form of the game when these variables are used.

\subsection{Summary}

Many of the above previous studies focused on the production decision-making of the supply chain under constraints of production capacity and the coordination of the supply chain. This paper studies the issue of cooperative advertising between manufacturers and retailers under constraint of production capacity. The study did not focus on the impact of order quantity or price in the supply chain. The focus was on how to coordinate the cost of advertising investment between the retailer and the retailer when the manufacturer faced the issue of capacity constraints, and how production capacity affected the two about cooperation of advertising input costs.

The previous studies mostly analyzed the influence of cooperative advertising on each member and system of the supply chain. This study has also considered the condition of the capacity constraint on the basis of the previous study. This can further enrich the research on the supply chain cooperation advertising mechanism.

The practical significance of this article is to provide certain decision-making suggestions for the company's cooperative advertising strategy. Due to a variety of factors, the demand forecast is more and more difficult. However, this study considers practical considerations and solves the actual decision-making problems of many enterprises under the goal of maximum corporate profits. Therefore, it can provide theoretical basis and practical guidance for enterprises.

\section{Model Descriptions and Assumptions}

Companies need to promote advertising in order to promote the sales of products. After the manufacturer gives the product to the retailer, the retailer then promotes the purchase of the product through advertising. This chapter considers the following two-stage supply chain consisting of a manufacturer $\mathrm{M}$ and a retailer R. Produce a single product from manufacturer $M$, wholesale it to retailer $\mathrm{R}$, and sell it to consumers through retailer $\mathrm{R}$.

The retailer R purchases the product at the wholesale price $w$ from the manufacturer $M$, and sells it to the consumers in the market at a certain price $p$. At the same time, retailers will invest advertising costs $\alpha$ in order to educate consumers on the quality of their products to increase their product demand. In order to 
promote the enthusiasm of retailers in advertising, manufacturers $M$ are considering providing certain advertising subsidies to retailers $\mathrm{R}$ in the downstream of the supply chain. The advertising subsidy given by the manufacturer $M$ to the retailer $\mathrm{R}$ can be regarded as the manufacturer's assumption of a certain proportion $t$ of advertising expenses. Then $t$ is the advertising share ratio, and $t a$ is the advertising subsidy given by the manufacturer to the retailer (Figure 1).

According to the model description, this chapter has the following assumptions.

Assumption 1: Manufacturers and retailers are rational and their goal is to maximize their profits through decision-making.

Assumption 2: The model does not consider the manufacturer's production cost. The wholesale price that the manufacturer sells to the retailer is the profit of each product.

Assumption 3: The market's optimal demand will be related to the manufacturer's output and the retailer's order quantity. Through the decision of manufacturers and retailers, the market's optimal demand will eventually be equal to the manufacturer's output and the retailer's order quantity.

Assumption 4: When there is a shortage of capacity, the manufacturer has no other measures to increase the capacity, or to increase the cost of production.

Based on the calculation and analysis needs of the paper, the following detailed descriptions are used for the parameters used in the model.

$\theta$. Basic market size;

$p$ : Retailer's retail price;

$\beta$ : Price sensitivity factor;

a: Advertising cost;

$k$. Advertising performance coefficient;

w. Manufacturer's wholesale price;

t. Advertising cost share ratio;

$D$ : Market demand;

$\pi_{m}, \pi_{r}, \pi_{m+r}$ : The profits of manufacturers, retailers, supply chain system;

$N$ : Capacity Constraints.

In addition, for the convenience of presentation, $X^{i_{j}{ }^{*}} \mathrm{~s}$ used to represent the optimal value of the variable $X$ in the $i$-game model when the production

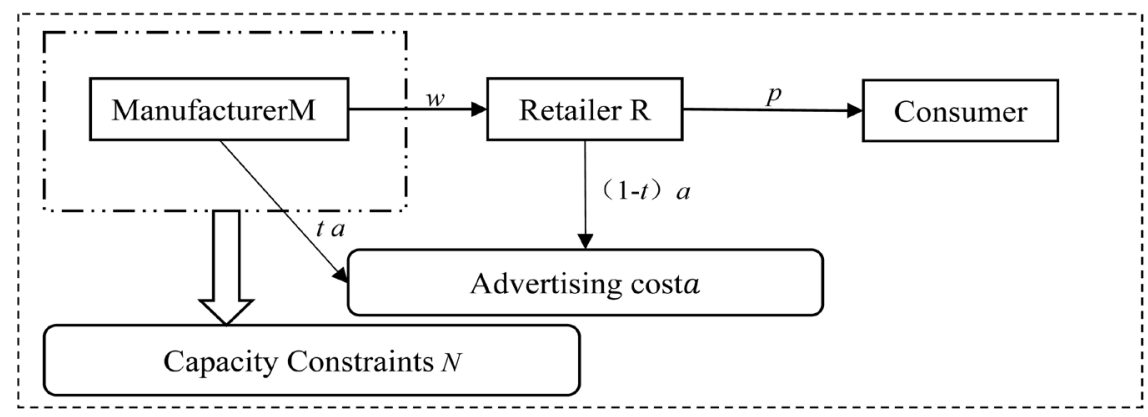

Figure 1. Supply chain cooperative advertising model under capacity constraints (Data source: Draw it by myself). 
capacity is in the $j$ state, where

$$
\begin{gathered}
i= \begin{cases}s, & \text { Stackelberg game } \\
h, & \text { Partnership game }\end{cases} \\
j= \begin{cases}0, & \text { No capacity constraint } \\
1, & \text { Capacity constraints }\end{cases}
\end{gathered}
$$

\section{Analysis}

\subsection{Supply Chain Cooperative Advertising Model without Capacity Constraints}

In the cooperative advertising model, it should be noted that for retailers, once the product sales reach a certain level, if the retailer blindly adds advertising, it will not only increase sales, but will increase production costs and marketing costs, causing a huge waste. Therefore, advertising expenditure and product sales are actually not a simple linear relationship but have a marginal diminishing effect.

Therefore, in this study, with reference to Xie and Wei [2], the basic cooperative advertising demand function is assumed to be:

$$
D=(\theta-\beta p) \cdot k \sqrt{a}
$$

where $\theta$ is the basic market size and $\beta$ is the price-sensitive coefficient. $a$ is the cost of advertising, and $k$ is the coefficient of advertising effectiveness. $k \sqrt{a}$ means the effect of advertising on demand.

If the manufacturer does not have a production capacity limit, the product can be produced indefinitely to the retailer. At this time, it is only necessary to consider the optimal decision in the market. At the same time, because manufacturers have more say and dominate the market, in the Stackelberg non-cooperative game, the decision is made first by the manufacturer, and then the retailer makes its own optimal decision. The ultimate goal is to both of the supply chain systems can get the best profits.

The manufacturer $M$ profit function is:

$$
\begin{gathered}
\pi_{m}=w D-t a \\
\text { s.t. } 0<w<p, 0 \leq t \leq 1 .
\end{gathered}
$$

The retailer $\mathrm{R}$ profit function is:

$$
\begin{aligned}
\pi_{r}= & (p-w) D-(1-t) a \\
& \text { s.t. } 0<p<\theta / \beta, a \geq 0 .
\end{aligned}
$$

Solve the retailer's profit function (4) and let the function perform a derivation of $p$ and $a$, Let $\frac{\partial \pi_{r}}{\partial p}=\frac{\partial \pi_{r}}{\partial a}=0$ to obtain the optimal solution:

$$
p^{s_{0} *}=\frac{w \beta+\theta}{2 \beta}, a^{s_{0} *}=\frac{k^{2}(w \beta-\theta)^{4}}{64(1-t)^{2} \beta^{2}} .
$$

Substituting the manufacturer's profit function: 


$$
\pi_{m}=\frac{k^{2}(w \beta-\theta)^{3}((-4+3 t) w \beta+t \theta)}{64(-1+t)^{2} \beta^{2}}
$$

Let $\frac{\partial \pi_{m}}{\partial w}=\frac{\partial \pi_{m}}{\partial a}=0$ to obtain the unique solution:

$$
w^{s_{0} *}=\frac{\theta}{3 \beta}, t^{s_{0}^{*}}=\frac{1}{3} .
$$

Substitute it into the retail price and advertising costs are available:

$$
\begin{gathered}
p^{s_{0} *}=\frac{2 \theta}{3 \beta}, a^{s_{0} *}=\frac{k^{2} \theta^{4}}{144 \beta^{2}} . \\
D^{s_{0} *}=\frac{k^{2} \theta^{3}}{36 \beta} .
\end{gathered}
$$

The optimal profits of manufacturers, retailers, and supply chain systems are:

$$
\begin{aligned}
\pi_{m}^{s_{0} *} & =\frac{k^{2} \theta^{4}}{144 \beta^{2}} ; \\
\pi_{r}^{s_{0} *} & =\frac{k^{2} \theta^{4}}{216 \beta^{2}} ; \\
\pi_{m+r}^{s_{0} *} & =\frac{5 k^{2} \theta^{4}}{432 \beta^{2}} .
\end{aligned}
$$

Proposition 1. If the retailer does not cooperate with the manufacturer, the retail price of the retailer will be twice the wholesale price of the manufacturer. In addition, manufacturers will choose to share $1 / 3$ of the advertising costs invested by retailers to boost market demand.

When manufacturers and retailers cooperate, the supply chain system objective function is:

$$
\begin{gathered}
\pi_{m+r}=p D-a \\
\text { s.t. } 0<p<\theta / \beta, a \geq 0 .
\end{gathered}
$$

Let $\frac{\partial \pi_{m+r}}{\partial w}=\frac{\partial \pi_{m+r}}{\partial a}=0$ to obtain the unique solution:

$$
\begin{gathered}
p^{s_{0}^{*}}=\frac{2 \theta}{3 \beta} ; \\
a^{s_{0}^{*}}=\frac{k^{2} \theta^{4}}{144 \beta^{2}} ; \\
D^{h_{0}^{*}}=\frac{k^{2} \theta^{3}}{16 \beta} ; \\
\pi_{m+r}^{h_{0} *}=\frac{k^{2} \theta^{4}}{64 \beta^{2}} .
\end{gathered}
$$

The above two models have already calculated the equilibrium solutions of each game. The following Table 1 shows the results of the basic supply chain 
Table 1. Supply chain cooperation advertising model equilibrium solution (without capacity constraints).

\begin{tabular}{ccc}
\hline Variable & Stackelberg game & Partnership game \\
\hline$p^{*}$ & $\frac{2 \theta}{3 \beta}$ & $\frac{\theta}{2 \beta}$ \\
$a^{*}$ & $\frac{k^{2} \theta^{4}}{144 \beta^{2}}$ & $\frac{k^{2} \theta^{4}}{64 \beta^{2}}$ \\
$w^{*}$ & $\frac{\theta}{3 \beta}$ & \\
$t^{*}$ & $\frac{1}{3}$ & \\
$D^{*}$ & $\frac{k^{2} \theta^{3}}{36 \beta}$ & \\
$\pi_{m}^{*}$ & $\frac{k^{2} \theta^{4}}{144 \beta^{2}}$ \\
$\pi_{r}^{*}$ & $\frac{k^{2} \theta^{4}}{216 \beta^{2}}$ & \\
$\pi_{m+r}^{*}$ & $\frac{5 k^{2} \theta^{4}}{432 \beta^{2}}$ & $\frac{k^{2} \theta^{4}}{64 \beta^{2}}$ \\
\hline
\end{tabular}

cooperation advertising model in the Stackelberg non-cooperative game and cooperation game.

\section{Proposition 2.}

1) $p^{s_{0}^{*}}-p^{h_{0} *}=-\frac{\theta}{6 \beta}>0$;

2) $a^{s_{0}^{*}}-a^{h_{0} *}=-\frac{5 k^{2} \theta^{4}}{576 \beta^{2}}<0$;

3) $D^{s_{0} *}-D^{h_{0} *}=-\frac{5 k^{2} \theta^{3}}{144 \beta}<0$;

4) $\pi_{m+r}^{s_{0}^{*}}-\pi_{m+r}^{h_{0}^{*} *}=-\frac{7 k^{2} \theta^{4}}{1728 \beta^{2}}<0$.

Proposition 2 shows that when the production capacity is unconstrained, if the retailer and the manufacturer choose to cooperate, the retail price of the product will be reduced, while increasing the advertising input costs, so that the optimal demand in the market will increase, and ultimately will make the entire supply chain profit rise.

\subsection{Supply Chain Cooperative Advertising Model under Capacity Constraints}

Retailers invest in advertising to promote demand growth and increase sales. However, demand must always be fully converted into sales. There is always a limit on production capacity. The limited production capacity directly constrains manufacturers' production activities, which in turn causes manufacturers to the profit that can be obtained is reduced, so consider considering the decision-making problem of the enterprise under the constraint of production capacity. 
Assume that the manufacturer's capacity is $N$, if the optimal demand is greater than $N$, but the manufacturer's production capacity limit leads to the maximum market sales can only be $N$, we need to consider the case of the production capacity of $N$. By adjusting $p$, $a$ at this time, the sales volume will ultimately optimize the profits of retailers, manufacturers, and supply chains, and all members will be able to make optimal decisions.

There is a constraint $D \leq N$ in this model, i.e.

$$
(\theta-\beta p) k \sqrt{a} \leq N
$$

The range of retail price $p$ is:

$$
\frac{\theta}{\beta}-\frac{N}{\beta k \sqrt{a}} \leq p \leq \frac{\theta}{\beta}
$$

Because there is a constraint on the production capacity $N$, the largest sales volume in the market can only be $N$. Therefore, it is necessary to adjust each variable to influence the market demand and finally obtain the optimal value. In the above model calculation, an optimal market demand $D^{*}$ under unconstrained conditions has been obtained, which is a critical value. When $N<D^{*}$, it is the case of insufficient capacity.

\subsubsection{Stackelberg Game}

In the Stackelberg non-cooperative game model, the profit functions of manufacturers and retailers are:

$$
\begin{aligned}
& \pi_{m}=w D-t a \\
& \text { s.t. } 0<w<p, a>0,0 \leq t \leq 1 . \\
& \pi_{r}=(p-w) D-(1-t) a \\
& \text { s.t. } \frac{\theta}{\beta}-\frac{N}{\beta k \sqrt{a}}<p<\frac{\theta}{\beta} .
\end{aligned}
$$

In this model, when the manufacturer's production capacity is $N<D^{s_{0} *}=\frac{k^{2} \theta^{3}}{36 \beta}$, that is, the capacity is insufficient, each variable needs to obtain the optimal value under the constraint condition, and the retailer needs to adjust. The retail price $p$ of the product and the advertising expense $a$, the manufacturer needs to adjust the wholesale price $w$ and advertising cost share ratio $t$.

The value range of the retail price $p: \frac{\theta}{\beta}-\frac{N}{\beta k \sqrt{a}} \leq p \leq \frac{\theta}{\beta}$. The retailer's optimal retail price and advertising cost without capacity constraints are: $p^{s_{0} *}=\frac{\theta}{2 \beta}+\frac{w}{2}, a^{s_{0} *}=\frac{k^{2}(\theta-w \beta)^{4}}{64(1-t)^{2} \beta^{2}}$. Then the retail price needs to meet the constraints $\frac{\theta}{\beta}-\frac{N}{\beta k \sqrt{a}} \leq p^{s_{0} *}$.

Case 1: $\frac{\theta}{\beta}-\frac{N}{\beta k \sqrt{a}} \leq \frac{\theta}{2 \beta}+\frac{w}{2}$ 
When $\frac{\theta}{\beta}-\frac{N}{\beta k \sqrt{a}} \leq \frac{\theta}{2 \beta}+\frac{w}{2}, \quad p^{s_{1} *}=\frac{\theta}{2 \beta}+\frac{w}{2}$, so $a \leq \frac{4 N^{2}}{k^{2}(\theta-\beta w)^{2}}$ can be obtained from this inequality. When $p^{s_{1}^{*}}=\frac{\theta}{2 \beta}+\frac{w}{2}$, it is easy to get the optimal advertising cost $a^{*}=\frac{k^{2}(\theta-w \beta)^{4}}{64(1-t)^{2} \beta^{2}}$. However, it is necessary to consider the range of variable $a$. So we do not consider this situation.

Case 1.1: $\frac{k^{2}(\theta-w \beta)^{4}}{64(1-t)^{2} \beta^{2}}<\frac{4 N^{2}}{k^{2}(\theta-\beta w)^{2}}$

$a^{s_{1} *}=\frac{k^{2}(\theta-w \beta)^{4}}{64(1-t)^{2} \beta^{2}}$, Substituting the optimal $p^{s_{1} *}$ and $a^{s_{1} *}$ into the manufacturer's profit function, the resulting wholesale price and the proportion of advertisement sharing are also the same as their optimal values under the constraint of no capacity, i.e., $w^{s_{1} *}=w^{s_{0} *}=\frac{\theta}{3 \beta}, t^{s_{1} *}=t^{s_{0} *}=\frac{1}{3}$,

when $N<\frac{k^{2} \theta^{3}}{36 \beta}$, variable a satisfy this condition

$a^{s_{1} *}=\frac{k^{2}(\theta-w \beta)^{4}}{64(1-t)^{2} \beta^{2}}<\frac{k^{2} \theta^{6}}{324 \beta^{2}(\theta-w \beta)^{2}}$ Substituting the optimal $w^{s_{1} *}$ and $t^{s_{1} *}$ into an inequality, $a^{s_{1} *}=\frac{k^{2} \theta^{4}}{144 \beta^{2}}<\frac{k^{2} \theta^{6}}{324 \beta^{2}(\theta-w \beta)^{2}}=\frac{k^{2} \theta^{4}}{144 \beta^{2}}$. This formula is not valid.

Case 1.2: $\frac{k^{2}(\theta-w \beta)^{4}}{64(1-t)^{2} \beta^{2}} \geq \frac{4 N^{2}}{k^{2}(\theta-\beta w)^{2}}$

At this point, the value of the optimal advertising input cost is not within its constraints, so it is necessary to analyze the retailer's profit function.

$$
\pi_{r}=\frac{\sqrt{a} k(\theta-w \beta)^{2}}{4 \beta}-(1-t) a
$$

The retailer's profit function is a quadratic function with an opening down of $\sqrt{a}$. When $a>a^{*}$ the function value will gradually decrease as variable $\alpha$ increases, so the function can obtain the maximum value at $a=\frac{4 N^{2}}{k^{2}(\theta-\beta w)^{2}}$, substituting it into the manufacturer's profit function is:

$$
\pi_{m}=N w-\frac{4 N^{2} t}{k^{2}(\theta-w \beta)^{2}}
$$

The profit function is then separately derived from the wholesale price $w$ and the share of advertising costs $t$.

$$
\frac{\partial \pi_{m}}{\partial w}=N-\frac{8 N^{2} t \beta}{k^{2}(\theta-w \beta)^{3}} ;
$$




$$
\frac{\partial \pi_{m}}{\partial t}=-\frac{4 N^{2}}{k^{2}(\theta-w \beta)^{2}} .
$$

The manufacturer's profit function can achieve the maximum value when the share of advertising costs $t$ is the minimum. Since $0 \leq t \leq 1, t^{s_{1}{ }^{*}}=0$, at this time, the manufacturer's profit function is simply: $\pi_{m}=N w$, the manufacturer's profit will increase with the increase of the wholesale price.

Combine the value range of $w: 0<w<p$, according to inequality $\frac{k^{2}(\theta-w \beta)^{4}}{64(1-t)^{2} \beta^{2}} \geq \frac{4 N^{2}}{k^{2}(\theta-\beta w)^{2}}, \quad w \leq \frac{\theta}{\beta}-2^{4 / 3}\left(\frac{(1-t) N}{k^{2} \beta^{2}}\right)^{1 / 3}$. So the manufacturer's maximum profit value can be obtained when $w=\frac{\theta}{\beta}-2^{4 / 3}\left(\frac{(1-t) N}{k^{2} \beta^{2}}\right)^{1 / 3}$. Thus we can draw a conclusion 1 .

Conclusion 1.

$$
\begin{aligned}
& p^{s_{1}^{*}}=\frac{\theta}{\beta}-\left(\frac{2 N}{k^{2} \beta^{2}}\right)^{1 / 3}, a^{s_{1}^{*}}=\left(\frac{N^{2}}{2 k \beta}\right)^{2 / 3}, w^{s_{1} *}=\frac{\theta}{\beta}-2^{4 / 3}\left(\frac{N}{k^{2} \beta^{2}}\right)^{1 / 3}, t^{s_{1} *}=0, \\
& D^{s_{1} *}=N, \pi_{m}^{s_{1}^{*}}=\frac{N \theta}{\beta}-4\left(\frac{N^{2}}{2 k \beta}\right)^{2 / 3}, \pi_{r}^{S_{1}^{*}}=\left(\frac{N^{2}}{2 k \beta}\right)^{2 / 3}, \pi_{m+r}^{s_{1} *}=\frac{N \theta}{\beta}-3\left(\frac{N^{2}}{2 k \beta}\right)^{2 / 3} .
\end{aligned}
$$

Subject to $0<N<\frac{k^{2} \theta^{3}}{36 \beta}$.

Case 2: $\frac{\theta}{\beta}-\frac{N}{\beta k \sqrt{a}}>\frac{\theta}{2 \beta}+\frac{w}{2}$

When $\frac{\theta}{\beta}-\frac{N}{\beta k \sqrt{a}}>\frac{\theta}{2 \beta}+\frac{w}{2}, \quad p^{s_{1} *}=\frac{\theta}{\beta}-\frac{N}{\beta k \sqrt{a}}$. We can simplify the retailer's profit function:

$$
\pi_{r}=N\left(\frac{\theta}{\beta}-w\right)-\frac{N^{2}}{\beta k \sqrt{a}}-(1-t) a
$$

The optimal advertising cost is $a^{*}=\left(\frac{N^{2}}{2 k \beta(1-t)}\right)^{2 / 3}$. A value range of variablea can be obtained from inequality $\frac{\theta}{\beta}-\frac{N}{\beta k \sqrt{a}}>\frac{\theta}{2 \beta}+\frac{w}{2}$ : $a>\frac{4 N^{2}}{k^{2}(\theta-\beta w)^{2}}$.

Case 2.1: $\left(\frac{N^{2}}{2 k \beta(1-t)}\right)^{2 / 3} \geqslant \frac{4 N^{2}}{k^{2}(\theta-\beta w)^{2}}$

If the retailer's profit function can take $a^{s_{1}{ }^{*}}=a^{*}=\left(\frac{N^{2}}{2 k \beta(1-t)}\right)^{2 / 3}$ as the most optional advertising cost, then $p^{s_{1}^{*}}=\frac{\theta}{\beta}-\frac{N}{\beta k \sqrt{a}}=\frac{\theta}{\beta}-\left(\frac{2(1-t) N}{k^{2} \beta^{2}}\right)^{1 / 3}$. 
This can simplify the manufacturer's profit function:

$$
\pi_{m}=N w-t\left(\frac{N^{2}}{2(1-t) k \beta}\right)^{2 / 3}
$$

Similarly, through the analysis of the function, we can see that the

manufacturer's profit is optimal at $t^{s_{1} *}=0, w^{s_{1} *}=\frac{\theta}{\beta}-2^{4 / 3}\left(\frac{N}{k^{2} \beta^{2}}\right)^{1 / 3}$. Thus we can draw a conclusion 2 .

\section{Conclusion 2.}

$$
\begin{aligned}
& p^{s_{1} *}=\frac{\theta}{\beta}-\left(\frac{2 N}{k^{2} \beta^{2}}\right)^{1 / 3}, a^{s_{1} *}=\left(\frac{N^{2}}{2 k \beta}\right)^{2 / 3}, \\
& w^{s_{1} *}=\frac{\theta}{\beta}-2^{4 / 3}\left(\frac{N}{k^{2} \beta^{2}}\right)^{1 / 3}, t^{s_{1} *}=0 \\
& D^{s_{1} *}=N, \pi_{m}^{s_{1} *}=\frac{N \theta}{\beta}-4\left(\frac{N^{2}}{2 k \beta}\right)^{2 / 3}, \\
& \pi_{r}^{s_{1} *}=\left(\frac{N^{2}}{2 k \beta}\right)^{2 / 3}, \pi_{m+r}^{s_{1} *}=\frac{N \theta}{\beta}-3\left(\frac{N^{2}}{2 k \beta}\right)^{2 / 3} .
\end{aligned}
$$

subject to $0<N<\frac{k^{2} \theta^{3}}{36 \beta}$.

Comprehensive cases 1.2 and case 2.1 can be found in both cases: Conclusion 1 is the same as Conclusion 2 .

$$
\text { Case 2.2: }\left(\frac{N^{2}}{2 k \beta(1-t)}\right)^{2 / 3}<\frac{4 N^{2}}{k^{2}(\theta-\beta w)^{2}}
$$

The retailer's profit function can be optimized at $a=\frac{4 N^{2}}{k^{2}(\theta-\beta w)^{2}}$, rather than $a^{*}=\left(\frac{N^{2}}{2 k \beta(1-t)}\right)^{2 / 3}$. If $a^{s_{1} *}=\frac{4 N^{2}}{k^{2}(\theta-\beta w)^{2}}, \quad p^{s_{1} *}=\frac{\theta}{2 \beta}+\frac{w}{2}$. This is inconsistent with the range of retail prices we discuss. So we do not consider this situation.

Note that regardless of the manufacturer, retailer or supply chain profits are related to the maximum production capacity $N$, and the market's optimal demand is related to the manufacturer's production and retailer's order quantity, so need to check the manufacturer's production, retailer If the order quantity is equal to the market's optimal demand, then it is to check: 1) Whether the manufacturer can achieve the best profit when the manufacturer produces $N$ products at full capacity. 2) Whether the retailer will order according to the market's optimal demand will enable it to obtain the best profits. Only on the basis of satisfying these two conditions, the decision-making of each member of the supply chain is its optimal market decision. At this time, it is necessary to discuss the impact of the production constraint. 
The equilibrium solution to the manufacturer's profits is derived from $N$. It is analyzed that when $0<N<\frac{27 k^{2} \theta^{3}}{1024 \beta}$ manufacturer's profit increases monotonously, but when $\frac{27 k^{2} \theta^{3}}{1024 \beta} \leq N<D^{s_{0} *}=\frac{k^{2} \theta^{3}}{36 \beta}$ manufacturer's profit decreases monotonically.

Because in this non-cooperative situation, manufacturers aim to maximize their profits, even if the manufacturer's maximum capacity is greater, it will still control the production capacity at $N=\frac{27 k^{2} \theta^{3}}{1024 \beta}$. To ensure that their profits will not be lost.

The following propositions are obtained.

Proposition 3.

When $0<N<\frac{k^{2} \theta^{3}}{36 \beta}$, we get the result: $t^{s_{1} *}=0, D^{s_{1} *}=N$.

It shows that when the production capacity is insufficient, the manufacturer will choose not to provide any advertising subsidies to the retailer. The retailer is responsible for all advertising costs.

\section{Proposition 4.}

When $0<N<\frac{27 k^{2} \theta^{3}}{2048 \beta}$,

1) $\frac{\partial p^{s_{1} *}}{\partial N}=-\frac{2^{1 / 3}\left(\frac{N^{2}}{k \beta}\right)^{2 / 3}}{3 N^{2}}<0, \frac{\partial w^{s_{1} *}}{\partial N}=-\frac{2^{5 / 3} k^{2} \beta^{4}}{3\left(k^{4} N \beta^{7}\right)^{2 / 3}}<0$;

2) $\frac{\partial a^{s_{1} *}}{\partial N}=\frac{2^{4 / 3}\left(\frac{N^{2}}{k \beta}\right)^{2 / 3}}{3 N}>0$

3) $\frac{\partial D^{s_{1}^{*}}}{\partial N}=1>0$;

4) $\frac{\partial \pi_{m}^{s_{1} *}}{\partial N}=\frac{\theta}{\beta}-\frac{1}{3}\left(\frac{2048 N}{k^{2} \beta^{2}}\right)^{1 / 3}>0, \frac{\partial \pi_{r}^{s_{1}^{*}}}{\partial N}=\frac{2^{7 / 3}\left(2^{4 / 3}-1\right)}{3}\left(\frac{N}{k^{2} \beta^{2}}\right)^{1 / 3}>0$, $\frac{\partial \pi_{m+r}^{s_{1} *}}{\partial N}=\frac{\theta}{\beta}-\left(\frac{16 N}{k^{2} \beta^{2}}\right)^{1 / 3}>0$.

Proposition 4 shows that when the capacity is very small, the maximum production capacity of a manufacturer is its output, and the manufacturer sells all the products it produces to consumers through retailers.

1) Both the retail price of the retailer and the wholesale price of the manufacturer are negatively related to the production capacity;

2) Advertising input costs are positively related to production capacity;

3) The market's optimal demand is positively related to production capacity; 
4) Profits of manufacturers and retailers and profits of the supply chain are positively related to production capacity.

Proposition 5.

$$
\begin{aligned}
& p^{s_{1} *}=\frac{5 \theta}{8 \beta}, a^{s_{1} *}=\frac{81 k^{2} \theta^{4}}{16384 \beta^{2}}, w^{s_{1} *}=\frac{\theta}{4 \beta}, t^{s_{1} *}=0, D^{s_{1} *}=\frac{27 k^{2} \theta^{3}}{1024 \beta}, \\
& \pi_{m}^{s_{1} *}=\frac{27 k^{2} \theta^{4}}{4096 \beta^{2}}, \pi_{r}^{s_{1}^{*}}=\frac{81 k^{2} \theta^{4}}{16384 \beta^{2}}, \pi_{m+r}^{s_{1} *}=\frac{189 k^{2} \theta^{4}}{16384 \beta^{2}}
\end{aligned}
$$

subject to $\frac{27 k^{2} \theta^{3}}{1024 \beta} \leq N<\frac{k^{2} \theta^{3}}{36 \beta}$ (Table 2).

Proposition 5 shows that there is a capacity value, and even if the manufacturer's maximum capacity is greater than this value, the manufacturer will not choose to produce more products. In the case of insufficient capacity, when a manufacturer's company dominates the market, as a retailer, it is only after the manufacturer's decision to make its own optimal decision. Sometimes it is often accompanied by an implicit loss of profits in order to make certain concessions in cooperation with manufacturers.

\subsubsection{Partnership Game}

When manufacturers and retailers are cooperating with each other, they do not discuss the wholesale price, that is, there is no wholesale price in the model, and there is no advertising share of manufacturer's advertising to retailers. The profit function of the supply chain system is:

$$
\pi_{m+r}=p D-a
$$

Table 2. Stackelberg non-cooperative game model equilibrium solution (under capacity constraints).

\begin{tabular}{ccc}
\hline Variable & $0<N<\frac{27 k^{2} \theta^{3}}{1024 \beta}$ & $\frac{27 k^{2} \theta^{3}}{1024 \beta} \leq N<\frac{k^{2} \theta^{3}}{36 \beta}$ \\
\cline { 2 - 3 } & $\frac{\theta}{\beta}-\left(\frac{2 N}{k^{2} \beta^{2}}\right)^{1 / 3}$ & $\frac{5 \theta}{8 \beta}$ \\
$p^{*}$ & $\left(\frac{N^{2}}{2 k \beta}\right)^{2 / 3}$ & $\frac{81 k^{2} \theta^{4}}{16384 \beta^{2}}$ \\
$a^{*}$ & $\frac{\theta}{\beta}-2^{4 / 3}\left(\frac{N}{k^{2} \beta^{2}}\right)^{1 / 3}$ & $\frac{\theta}{4 \beta}$ \\
$t^{*}$ & 0 & 0 \\
$D^{*}$ & $N$ & $\frac{27 k^{2} \theta^{3}}{1024 \beta}$ \\
$\pi_{m}^{*}$ & $\frac{N \theta}{\beta}-4\left(\frac{N^{2}}{2 k \beta}\right)^{2 / 3}$ & $\frac{27 k^{2} \theta^{4}}{4096 \beta^{2}}$ \\
$\pi_{r}^{*}$ & $\left(\frac{N^{2}}{2 k \beta}\right)^{2 / 3}$ & $\frac{81 k^{2} \theta^{4}}{16384 \beta^{2}}$ \\
$\pi_{m+r}^{*}$ & $\frac{N \theta}{\beta}-3\left(\frac{N^{2}}{2 k \beta}\right)^{2 / 3}$ & $\frac{189 k^{2} \theta^{4}}{16384 \beta^{2}}$ \\
\hline
\end{tabular}




$$
\text { s.t. } \frac{\theta}{\beta}-\frac{N}{\beta k \sqrt{a}} \leq p \leq \frac{\theta}{\beta}, a>0 \text {. }
$$

Assuming $N<D^{h_{0} *}=\frac{k^{2} \theta^{3}}{16 \beta}$, that is, when the production capacity is insufficient to meet the demand, we adjust the retail price of the product and the advertising costs invested. At this time, the decision maker can choose to: increase the retail price or reduce the investment. Advertising costs maximize their profits by saving costs.

Calculate retailer's profit function $\pi_{r}=p(\theta-\beta p) k \sqrt{a}-a$, we can get the equilibrium solution: $p^{*}=\frac{\theta}{2 \beta}, a^{*}=\frac{k^{2} \theta^{4}}{64 \beta^{2}}$. The range of retail price $p$ is $\frac{\theta}{\beta}-\frac{N}{\beta k \sqrt{a}} \leq p \leq \frac{\theta}{\beta}$. Here we need to discuss whether $p^{*}$ is within the range of retail prices.

Case 1: $\frac{\theta}{\beta}-\frac{N}{\beta k \sqrt{a}}<\frac{\theta}{2 \beta}$

The optimal retail price is $p^{h_{1} *}=p^{*}=\frac{\theta}{2 \beta}$. Calculated according to the derivation of the profit function: $a^{h_{1} *}=a^{*}=\frac{k^{2} \theta^{4}}{64 \beta^{2}}$. From $\frac{\theta}{\beta}-\frac{N}{\beta k \sqrt{a}}<\frac{\theta}{2 \beta}$, $a<\frac{4 N^{2}}{k^{2} \theta^{2}}$ can be obtained. Since $N<\frac{k^{2} \theta^{3}}{16 \beta}, \frac{4 N^{2}}{k^{2} \theta^{2}}<a^{*}=\frac{k^{2} \theta^{4}}{64 \beta^{2}}$. So $a^{*}=\frac{k^{2} \theta^{4}}{64 \beta^{2}}$ is not within the constraint range. Therefore, the situation was abandoned.

Case 2: $\frac{\theta}{\beta}-\frac{N}{\beta k \sqrt{a}} \geq \frac{\theta}{2 \beta}$

When $\frac{\theta}{\beta}-\frac{N}{\beta k \sqrt{a}} \geq \frac{\theta}{2 \beta}$, i.e., $a \geq \frac{4 N^{2}}{k^{2} \theta^{2}}$. The profit function $\pi_{m+r}=p(\theta-\beta p) k \sqrt{a}-a$ cannot obtain $p^{*}=\frac{\theta}{2 \beta}$, the profit function decreases monotonically within the range of $\frac{\theta}{\beta}-\frac{N}{\beta k \sqrt{a}} \leq p \leq \frac{\theta}{\beta}$. So the optimal retail price is $p=\frac{\theta}{\beta}-\frac{N}{\beta k \sqrt{a}}$.

Simplify the profit function:

$$
\pi_{m+r}=\left(\frac{\theta}{\beta}-\frac{N}{\beta k \sqrt{a}}\right) N-a
$$

By taking $\frac{\partial \pi_{m+r}}{\partial a}=0$, we obtain $\sqrt{a}=\left(\frac{N^{2}}{2 k \beta}\right)^{1 / 3}$. Here we need to check whether $a^{*}=\left(\frac{N^{2}}{2 k \beta}\right)^{2 / 3}$ satisfies $a \geq \frac{4 N^{2}}{k^{2} \theta^{2}}$. Note that when $0<N<\frac{k^{2} \theta^{3}}{16 \beta}$, 
$\left(\frac{N^{2}}{2 k \beta}\right)^{2 / 3}>\frac{4 N^{2}}{k^{2} \theta^{2}}$ that shows that the profit function can take $a^{*}=\left(\frac{N^{2}}{2 k \beta}\right)^{2 / 3}$. We can draw a conclusion 3 .

Conclusion 3.

$$
p^{h_{1} *}=\frac{\theta}{\beta}-\left(\frac{2 N}{k^{2} \beta^{2}}\right)^{1 / 3}, a^{h_{1} *}=\left(\frac{N^{2}}{2 k \beta}\right)^{2 / 3}, D^{h_{1} *}=N, \pi_{m+r}^{h_{1} *}=\frac{N \theta}{\beta}-3\left(\frac{N^{2}}{2 k \beta}\right)^{2 / 3} .
$$

subject to $0<N<\frac{k^{2} \theta^{3}}{16 \beta}$ (Table 3 ).

\section{Proposition 6.}

When $0<N<\frac{27 k^{2} \theta^{3}}{2048 \beta}$,

1) $\frac{\partial p^{h_{1} *}}{\partial N}=-\frac{2^{1 / 3}\left(\frac{N^{2}}{k \beta}\right)^{2 / 3}}{3 N^{2}}<0$;

2) $\frac{\partial a^{h_{1} *}}{\partial N}=\frac{2^{4 / 3}\left(\frac{N^{2}}{k \beta}\right)^{2 / 3}}{3 N}>0$;

3) $\frac{\partial D^{h_{1} *}}{\partial N}=1>0$;

4) $\frac{\partial \pi_{m+r}^{h_{1} *}}{\partial N}=\frac{\theta}{\beta}-\left(\frac{16 N}{k^{2} \beta^{2}}\right)^{1 / 3}>0$.

Proposition 6 indicates that in the case of insufficient capacity, when manufacturers and retailers choose to cooperate, they no longer consider the manufacturer's wholesale price and the manufacturer's advertising subsidies for retailers. As manufacturers' production capacity increases, retailers will choose to increase the retail price of their products, increase advertising costs, and increase product demand.

\section{Conclusions and Managerial Implications}

In this paper, the manufacturer is the dominant company in this supply chain

Table 3. Partnership game model equilibrium solution (under capacity constraints).

\begin{tabular}{cc}
\hline Variable & $N$ \\
\cline { 2 - 2 } & $0<N<\frac{k^{2} \theta^{3}}{16 \beta}$ \\
\hline$p^{*}$ & $\frac{\theta}{\beta}-\left(\frac{2 N}{k^{2} \beta^{2}}\right)^{1 / 3}$ \\
$a^{*}$ & $\left(\frac{N^{2}}{2 k \beta}\right)^{2 / 3}$ \\
$D^{*}$ & $N$ \\
$\pi_{m+r}^{*}$ & $\frac{N \theta}{\beta}-3\left(\frac{N^{2}}{2 k \beta}\right)^{2 / 3}$ \\
\hline
\end{tabular}


consisting of a single manufacturer and a single retailer. Through the establishment of a supply chain model based on cooperative advertising, the supply chain model is established to consider the unconstrained and constrained conditions respectively to analyze the production capacity, and the impact of advertising on the outcomes of each member of the supply chain and the overall supply chain. In addition, Stackelberg non-cooperative game model and Partnership game model are also established in each case to investigate whether cooperation under the constraint of production capacity has an impact on the decisions of retailers and manufacturers.

In the presence of capacity constraint, if the capacity is insufficient, the optimal market demand of the product is that all the products produced by the manufacturer can be purchased by the retailer, but not how much production capacity the manufacturer will produce, when the production capacity reaches a certain value. If the output of the production is further increased, the profit of the manufacturer will be reduced. Therefore, at this time, the manufacturer will not expand its production capacity, and the optimal market demand will be maintained at a fixed value. In the case of sufficient capacity, the optimal demand of the market is greatly enhanced because it is no longer subject to capacity constraints.

In order to achieve optimal market demand, one of the decisions of retailers and manufacturers is to reduce their retail price and wholesale price. If the two do not choose to cooperate, when the production capacity is relatively small, the retail price and the wholesale price are relatively high. As the production capacity continues to increase, the pressure on the manufacturers to increase demand will be even greater, and the wholesale price must be greatly reduced. In order to ensure that all the products produced are sold, this leads to a gradual slowdown in their profit growth, while for retailers, they can get more profits than manufacturers. When manufacturers' profits no longer increase, manufacturers will choose not to produce products anymore. At this time, the decision-making results of manufacturers and retailers will remain at a certain value.

When the production capacity is insufficient, manufacturers will not actively share the advertising input costs of retailers. Retailers are responsible for all product advertising. If the production capacity is gradually increased, the advertising costs incurred will increase, regardless of the cooperation. The retailer's investment is the same. When the production capacity is sufficient, the manufacturer will choose to give the retailer a certain amount of advertising subsidies which is one-third of the retailer's advertising costs. In this way, the retailer will vigorously promote the product and increase the product demand eventually.

From the perspective of the supply chain as a whole, when the production capacity is small, cooperation or non-cooperation between the retailer and the manufacturer will not affect the decision of the manufacturer and the retailer, nor will the overall profit of the supply chain be improved. When the production capacity is sufficient, if the retailer and the manufacturer cooperate, the retail 
price of the product will be reduced, and the advertising cost of the product promotion will be increased. The market demand will be increased to a certain extent, and eventually the profit of the entire supply chain system will increase.

This article establishes some assumptions in the establishment of the model, so most of the conclusions are based on assumptions. At the same time, this article can also be further analyzed from other aspects. Subsequent research may also consider how the decisions of manufacturers and retailers will change when retailers dominate the market and manufacturers follow. Furthermore, it is also possible to establish a bargaining model to explore the profit distribution problems of manufacturers and retailers under the partnership game model, and eventually realize the coordination of the supply chain.

\section{References}

[1] Berger, P.D. (1972) Vertical Cooperative Advertising Ventures. Journal of Marketing Research, 9, 309-312. https://doi.org/10.2307/3149542

[2] Huang, Z. and Li, S.X. (2001) Co-Op Advertising Models in Manufacturer-Retailer Supply Chains: A Game Theory Approach. European Journal of Operational Research, 135, 527-544. https://doi.org/10.1016/S0377-2217(00)00327-1

[3] Xie, J. and Wei, J.C. (2009) Coordinating Advertising and Pricing in a Manufacturer-Retailer Channel. European Journal of Operational Research, 197, 785-791. https://doi.org/10.1016/j.ejor.2008.07.014

[4] Karray, S. and Amin, S.H. (2015) Cooperative Advertising in a Supply Chain with Retail Competition. International Journal of Production Research, 53, 88-105. https://doi.org/10.1080/00207543.2014.925602

[5] Zhang, J., Xie, J. and Chen, B. (2013) Cooperative Advertising with Bilateral Participation. Decision Sciences, 44, 193-203.

[6] Jørgensen, S., Sigué, S.P. and Zaccour, G. (2000) Dynamic Cooperative Advertising in a Channel. Journal of Retailing, 76, 71-92. https://doi.org/10.1016/S0022-4359(99)00024-X

[7] Jørgensen, S. and Zaccour, G. (2014) A Survey of Game-Theoretic Models of Cooperative Advertising. European Journal of Operational Research, 237, 1-14. https://doi.org/10.1016/j.ejor.2013.12.017

[8] He, X., Prasad, A. and Sethi, S.P. (2009) Cooperative Advertising and Pricing in a Dynamic Stochastic Supply Chain: Feedback Stackelberg Strategies. Production and Operations Management, 18, 78-94. https://doi.org/10.1111/j.1937-5956.2009.01006.x

[9] Bergen, M. and John, G. (1997) Understanding Cooperative Advertising Participation Rates in Conventional Channels. Journal of Marketing Research, 34, 357-369. https://doi.org/10.2307/3151898

[10] Karray, S. and Zaccour, G. (2003) Coop Advertising Programs under Competitive Market Structures. Groupe d'études et de recherche en analyse des décisions, HEC, Montréal.

[11] Cachon, G.P. and Lariviere, M.A. (1999) Capacity Choice and Allocation: Strategic Behavior and Supply Chain Performance. Management Science, 45, 1091-1108. https://doi.org/10.1287/mnsc.45.8.1091

[12] Florian, M. and Klein, M. (1971) Deterministic Production Planning with Concave Costs and Capacity Constraints. Management Science, 18, 12-20. 
https://doi.org/10.1287/mnsc.18.1.12

[13] Jonrinaldi and Zhang, D.Z. (2013) An Integrated Production and Inventory Model for a Whole Manufacturing Supply Chain Involving Reverse Logistics with Finite Horizon Period. Omega, 41, 598-620. https://doi.org/10.1016/j.omega.2012.07.001

[14] Li, Y., Chen, J. and Cai, X. (2007) Heuristic Genetic Algorithm for Capacitated Production Planning Problems with Batch Processing and Remanufacturing. International Journal of Production Economics, 105, 301-317.

https://doi.org/10.1016/j.ijpe.2004.11.017

[15] Hsieh, C. and Wu, C. (2008) Capacity Allocation, Ordering, and Pricing Decisions in a Supply Chain with Demand and Supply Uncertainties. European Journal of Operational Research, 184, 667-684. https://doi.org/10.1016/j.ejor.2006.11.004

[16] Kreps, D.M. and Scheinkman, J.A. (1983) Quantity Precommitment and Bertrand Competition Yield Cournot Outcomes. The Bell Journal of Economics, 14, 326-337. https://doi.org/10.2307/3003636 